RMD

Open

Rheumatic \&

Musculoskeletal

Diseases

\title{
Non-surgical management of knee osteoarthritis: where are we now and where do we need to go?
}

\author{
Frank Buttgereit, ${ }^{1}$ Gerd-Rüdiger Burmester, ${ }^{1}$ Johannes W J Bijlsma ${ }^{2}$
}

To cite: Buttgereit $F$, Burmester G-R, Bijlsma JWJ. Non-surgical management of knee osteoarthritis: where are we now and where do we need to go?. RMD Open 2014;1:e000027. doi:10.1136/rmdopen-2014000027

- Prepublication history and this paper is available online. To view these files please visit the journal online (http://dx.doi.org/10.1136/ rmdopen-2014-000027)

Received 27 November 2014 Revised 4 December 2014 Accepted 12 December 2014

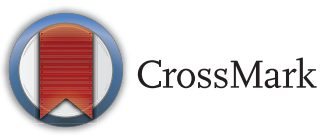

\section{${ }^{1}$ Department of Rheumatology \& Clinical Immunology, Charité University Medicine Berlin, German Rheumatism Research Center (DRFZ) and Berlin-Brandenburg Center of Regenerative Therapies (BCRT), Berlin, Germany ${ }^{2}$ Department of Rheumatology \& Clinical Immunology, University Medical Center Utrecht, Utrecht, The Netherlands}

Correspondence to Professor Frank Buttgereit; frank.buttgereit@charite.de

\section{ABSTRACT}

After the successful treatment of inflammatory rheumatic diseases with targeted therapies, the greatest challenge in rheumatic diseases remains the treatment of the most common chronic joint disorder, osteoarthritis. Osteoarthritis (OA) commonly affects the knee, with an age-standardised and sex-standardised incidence of 240 per 100.000 person-years. With the aging of the population and rising obesity throughout the world, it is anticipated that the burden of OA will increase and become a major problem for health systems globally. Given this background, proper guidance on the management of $O A$ is needed. This issue has been addressed over recent months in updated guidelines or recommendations detailing three treatment modalities: non-pharmacological, pharmacological and surgical. It should be noted, that $O A$ is not a uniform disease entity. In some patients, progression of the disease seems to be driven by cartilage factors, in others by bone factors or by inflammatory factors. Ongoing research aims to identify potential biomarkers for these different forms of $O A$. Research is also underway into disease modifying $O A$ drugs (DMOADs) that target different aspects of the disease, treatments for OA pain, and cell-based therapies.

After the successful treatment of inflammatory rheumatic diseases with targeted therapies, the greatest challenge in rheumatic diseases remains the treatment of the most common chronic joint disorder, osteoarthritis (OA). OA is one of the most prevalent chronic diseases worldwide. ${ }^{1}$ Globally, hip and knee $\mathrm{OA}$ is ranked as the 11th highest contributor to global disability (measured by years lived with disability), and as the 38th highest in terms of overall burden (as measured by disability-adjusted life years) in $2010 .^{2}$ With the aging of the population and rising obesity throughout the world, it is anticipated that the burden of $\mathrm{OA}$ will increase and become a major problem for health systems globally. ${ }^{2}$
OA commonly affects the knee, with an age-standardised and sex-standardised incidence of 240/100000 person-years. ${ }^{3}$ Over the age of 80 years, more than half of women and one-third of men suffer from radiographical OA of the knee. ${ }^{4}$ The global prevalence of radiographically confirmed knee OA (Kellgren-Lawrence grades 2-4) was very recently estimated to be $3.8 \%(4.8 \%$ in females; $2.8 \%$ in males) with a peak at around 50 years of age. ${ }^{2}$ These data are in agreement with the earlier observation that females are at a higher risk of knee OA than men. A recently published cross-sectional analysis found that women also experience greater knee pain than men, regardless of KellgrenLawrence grade. ${ }^{6}$ Pain, inflammatory flares, stiffness and loss of movement and function represent major symptoms of $\mathrm{OA}$ including knee OA, resulting in a substantial adverse impact on patients' quality of life and considerable economic burden. ${ }^{34} 7$

Given this background, proper guidance on the management of $\mathrm{OA}$ is needed. This issue has been addressed over recent months in updated guidelines or recommendations from the American Academy of Orthopaedic Surgeons (AAOS), American College of Rheumatology (ACR), European League against Rheumatism (EULAR) and European Society for Clinical and Economic Aspects of Osteoporosis and Osteoarthritis (ESCEO). ${ }^{8-11}$ In addition, the OA Research Society International (OARSI) guidelines for the nonsurgical management of knee OA were updated and published recently. ${ }^{12}$ While previous OARSI guidelines addressed the management of hip and knee OA, the updated guidelines focused specifically on the knee, evaluating the safety and efficacy profiles of currently available treatment options. ${ }^{12}$ Given the relative paucity of novel data, the authors took an innovative approach to enhance the specificity of treatment recommendations: they 


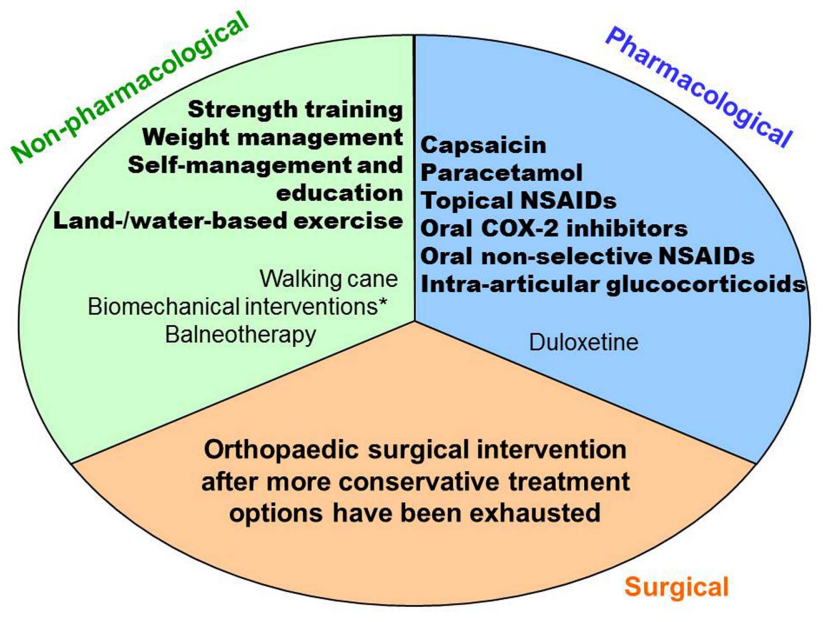

Figure 1 Treatments considered 'Appropriate' in at least one of the four subphenotypes of knee osteoarthritis. ${ }^{12}$ Quality of evidence is indicated by: bold=good; not bold=fair. NSAIDs, non-steroidal anti-inflammatory drug. ${ }^{*}$ knee braces, knee sleeves, foot orthoses and lateral wedge insoles.

defined OA clinical subphenotypes (knee-only OA with and without comorbidities; multijoint $\mathrm{OA}$ with and without comorbidities).

Commonly, we distinguish three treatment modalities: non-pharmacological, pharmacological and surgical. ${ }^{4}$ Figure 1 summarises treatments OARSI recommends are 'Appropriate' in at least one of the four subphenotypes. ${ }^{12}$
They suggest not using treatments rated 'Inappropriate' (eg, risedronate, electrotherapy), but others are rated 'Uncertain' (eg, acupuncture, chrondroitin, glucosamin or opioids). For the latter, the authors recommend physician-patient interaction to determine whether this treatment may have merit for an individual patient. Referral for consideration of orthopaedic surgical intervention is indicated after more conservative treatment options have been exhausted. ${ }^{12}$ Although both patients and doctors consider postponing surgery a success, for many patients joint replacement is eventually the final treatment option. ${ }^{13}$ This implies that, despite the variety of appropriate nonsurgical treatment options, there are still considerable limitations in either success rate or tolerability when treating established knee OA.

Excess weight and obesity are well-known risk factors for OA since they increase mechanical stress and induce systemic effects (eg,via adipokines and/or hyperglycaemia) involved in OA pathogenesis. ${ }^{14}$ It has been recently confirmed that in knee OA, mechanical stress is the most important underlying mechanism; this is in contrast to hand $\mathrm{OA}$, where systemic processes appear to be most important. ${ }^{14}$ In line with this are results of a meta-analysis published in July 2014 indicating that knee OA risk increases almost exponentially according to the increase in body mass index (BMI). ${ }^{15}$ Furthermore, analysis of data available through the Osteoarthritis Initiative and the CHECK-cohort confirmed that individuals with higher BMI experience greater pain from

Table 1 Studies investigating potential new non-surgical treatment options in knee OA (modified and updated from ${ }^{21}$ )

\begin{tabular}{|c|c|}
\hline Treatment option & Studies \\
\hline $\begin{array}{l}\text { DMOADs targeting } \\
\text { cartilage }\end{array}$ & $\begin{array}{l}\text { Intra-articular recombinant human fibrobla } \\
\text { factor } 18 \text { (NCT01919164) } \\
\text { Intra-articular TPX-100 (NCT1925261) }\end{array}$ \\
\hline $\begin{array}{l}\text { DMOADs targeting } \\
\text { bone }\end{array}$ & Oral strontium ranelate $e^{25-27}$ \\
\hline $\begin{array}{l}\text { DMOADs targeting } \\
\text { synovitis }\end{array}$ & $\begin{array}{l}\text { Oral hydroxychloroqine and atorvastatin } \\
\text { (NCT01645176) } \\
\text { Oral methotrexate (NCT01654575) } \\
\text { Oral SD-6010 (Cindunistat) }\end{array}$ \\
\hline & Subcutaneous ABT-981 (NCT01668511) \\
\hline & Oral PRX167700 (NCT01945346) \\
\hline $\begin{array}{l}\text { Treatments targeting } \\
\text { pain }\end{array}$ & $\begin{array}{l}\text { Tanezumab }^{29} \\
\text { CG100649 (NCT1765296) }\end{array}$ \\
\hline
\end{tabular}

AKR 202 (NCT02003118)

Cell-based therapies Allogenic mesenchymal stem cells (NCT01586312, NCT01985633, NCT01459640)

Mesenchymal trophic factor (NCT02003131)

Autologous adipose derived stem cells (NCT01585857) 
knee OA than individuals with lower BMI, even when taking into account OA severity. ${ }^{16}{ }^{17}$ Therefore, successful management of knee $\mathrm{OA}$ includes reduction of adverse mechanical factors (ie, weight loss in patients who are overweight or obese). ${ }^{11}$ Exercise is also beneficial, as shown in a recently published randomised controlled trial in women with OA of the knee. ${ }^{18}$ Progressive resistance exercise reduced pain, improved function, increased strength and showed benefits on some quality of life domains. ${ }^{18}$ However, apart from these approaches and education about the disease, there is little to offer patients for prevention or early treatment that is directed at the cause of the disease. ${ }^{19}$

Why have researchers failed so far to develop effective and safe disease modifying OA drugs (DMOADs) for the millions of patients suffering from this serious and disabling disease? One major reason is that pathogenesis of this disease is not fully understood. ${ }^{13} \mathrm{OA}$ is considered to result from failure of the repair of damaged cartilage. ${ }^{4}$ However, recent evidence shows an additional and integrated role of bone and synovial tissue, at least in some patients with OA. ${ }^{20}$ Clearly, OA is not a uniform disease entity. In some patients, progression of the disease seems to be driven by cartilage factors, in others by bone factors or by inflammatory factors. ${ }^{41}$ Ongoing research aims to identify potential biomarkers for cartilage-driven, bone-driven and synovitis-driven forms of OA. In a very recent intriguing study, Beyer et $a l^{22}$ identified differentially expressed miRNAs as predictors for severe knee and hip OA. This is an important observation since circulating miRNAs are easily accessible and stable. Only a few biomarkers that reflect bone and cartilage metabolism have shown value in predicting $\mathrm{OA},{ }^{23}$ and none has so far entered routine clinical practice. Therefore, specific miRNAs, such as let-7e, may prove useful biomarkers for OA. ${ }^{22}$ Research is also underway into DMOADs that target different aspects of the disease, treatments for OA pain and cell-based therapies; table 1 lists studies in these areas that we consider promising. Apart from these novel non-surgical approaches, a new surgical method is also in development-intrinsic cartilage repair by joint distraction. $^{21}$

Despite these widespread and promising current research activities, many questions about $\mathrm{OA}$ and its treatment still require answers (box 1). The EU has recognised rheumatic and musculoskeletal diseases as 'major diseases', which may trigger research. Priorities in OA research include predictors of progression, understanding mechanisms of pain and tissue communication, developing concepts and interventions for early $\mathrm{OA}$ and the need for new treatment strategies. ${ }^{24}$ This research agenda represents useful guidance for researchers in the field. We believe that putting as much effort into OA research as was seen in recent years in RA research may yield significant progress in improving quality of life for many patients with OA. Real possibilities are visible on the horizon.
Box 1 Challenges in the treatment of $\mathrm{OA}$

When does OA start and how can we define this time point?

Which programmes are most effective to educate patients about the benefits of current preventive measures (such as weight loss and exercise)?

- If a novel DMOAD is discovered how can we select patients who will benefit most (different phenotypes, different points of action)?

- If a novel DMOAD is discovered that needs to be administered before pronounced symptoms develop, will patients adhere to treatment when other preventive measures (such as weight loss and exercise) are currently poorly followed?

- When should surgery be recommended? At an early time point when quality of life is still good or at a later time because of economic restraints and the limited life span of endoprosthetic material?

- When will regenerative medicine (including tissue engineering) result in materials to repair damaged joints that provide an alternative to the metal and ceramics currently used?

\section{Competing interests None.}

Provenance and peer review Not commissioned; externally peer reviewed.

Data sharing statement No additional data are available.

Open Access This is an Open Access article distributed in accordance with the Creative Commons Attribution Non Commercial (CC BY-NC 4.0) license, which permits others to distribute, remix, adapt, build upon this work noncommercially, and license their derivative works on different terms, provided the original work is properly cited and the use is non-commercial. See: http:// creativecommons.org/licenses/by-nc/4.0/

\section{REFERENCES}

1. Busija L, Bridgett L, Williams SR, et al. Osteoarthritis. Best Pract Res Clin Rheumatol 2010;24:757-68.

2. Cross M, Smith E, Hoy D, et al. The global burden of hip and knee osteoarthritis: estimates from the Global Burden of Disease 2010 study. Ann Rheum Dis 2014;73:1323-30.

3. Oliveria SA, Felson DT, Reed JI, et al. Incidence of symptomatic hand, hip, and knee osteoarthritis among patients in a health maintenance organization. Arthritis Rheum 1995;38:1134-41.

4. Bijlsma JW, Berenbaum F, Lafeber FP. Osteoarthritis: an update with relevance for clinical practice. Lancet 2011;377:2115-26.

5. Srikanth VK, Fryer JL, Zhai G, et al. A meta-analysis of sex differences prevalence, incidence and severity of osteoarthritis. Osteoarthritis Cartilage 2005;13:769-81.

6. Glass N, Segal NA, Sluka KA, et al. Examining sex differences in knee pain: the Multicenter Osteoarthritis Study. Osteoarthritis Cartilage 2014;22:1100-6.

7. Rosemann T, Laux G, Szecsenyi J. Osteoarthritis: quality of life, comorbidities, medication and health service utilization assessed in a large sample of primary care patients. J Orthop Surg Res 2007;2:12.

8. Jevsevar DS, Brown GA, Jones DL, et al. The American Academy of Orthopaedic Surgeons evidence-based guideline on: treatment of osteoarthritis of the knee, 2nd edition. J Bone Joint Surg Am 2013;95:1885-6.

9. Hochberg MC, Altman RD, April KT, et al. American College of Rheumatology 2012 recommendations for the use of nonpharmacologic and pharmacologic therapies in osteoarthritis of the hand, hip, and knee. Arthritis Care Res (Hoboken) 2012;64:465-74.

10. Fernandes L, Hagen KB, Bijlsma JW, et al. EULAR recommendations for the non-pharmacological core management of hip and knee osteoarthritis. Ann Rheum Dis 2013;72:1125-35.

11. Bruyere O, Cooper C, Pelletier JP, et al. An algorithm recommendation for the management of knee osteoarthritis in Europe and internationally: a report from a task force of the European Society for Clinical and Economic Aspects of Osteoporosis and Osteoarthritis (ESCEO). Semin Arthritis Rheum 2014;44:253-63. 
12. McAlindon TE, Bannuru RR, Sullivan MC, et al. OARSI guidelines for the non-surgical management of knee osteoarthritis. Osteoarthritis Cartilage 2014;22:363-88.

13. Qvist P, Bay-Jensen AC, Christiansen C, et al. The disease modifying osteoarthritis drug (DMOAD): is it in the horizon? Pharmacol Res 2008;58:1-7.

14. Visser AW, de Mutsert R, le Cessie S, et al. The relative contribution of mechanical stress and systemic processes in different types of osteoarthritis: the NEO study. Ann Rheum Dis 2014. Published Online First: 20 May 2014. doi:10.1136/annrheumdis-2013-205012

15. Zhou ZY, Liu YK, Chen HL, et al. Body mass index and knee osteoarthritis risk: a dose-response meta-analysis. Obesity 2014;22:2180-5.

16. Weiss E. Knee osteoarthritis, body mass index and pain: data from the Osteoarthritis Initiative. Rheumatology 2014;53:2095-9.

17. Wesseling J, Bierma-Zeinstra SM, Kloppenburg M, et al. Worsening of pain and function over 5 years in individuals with 'early' $O A$ is related to structural damage: data from the Osteoarthritis Initiative and CHECK (Cohort Hip \& Cohort Knee) study. Ann Rheum Dis 2013. Published Online First: 15 Nov 2013. doi:10.1136/annrheumdis-2013203829

18. Jorge RT, Souza MC, Chiari A, et al. Progressive resistance exercise in women with osteoarthritis of the knee: a randomized controlled trial. Clin Rehabil 2014. [Epub ahead of print 3 Jul 2014].

19. Goldring MB, Goldring SR. Osteoarthritis. J Cell Physiol 2007:213:626-34.

20. Sellam J, Berenbaum F. The role of synovitis in pathophysiology and clinical symptoms of osteoarthritis. Nat Rev Rheumatol 2010;6:625-35

21. Mastbergen SC, Saris DB, Lafeber FP. Functional articular cartilage repair: here, near, or is the best approach not yet clear? Nat Rev Rheumatol 2013;9:277-90.
22. Beyer C, Zampetaki A, Lin NY, et al. Signature of circulating microRNAs in osteoarthritis. Ann Rheum Dis 2014. Published Online First: 27 Feb 2014. doi:10.1136/annrheumdis-2013-204698

23. Schett G, Kiechl S, Bonora E, et al. Vascular cell adhesion molecule 1 as a predictor of severe osteoarthritis of the hip and knee joints. Arthritis Rheum 2009;60:2381-9.

24. Conaghan PG, Kloppenburg M, Schett G, et al. Osteoarthritis research priorities: a report from a EULAR ad hoc expert committee. Ann Rheum Dis 2014;73:1442-5.

25. Reginster JY, Badurski J, Bellamy N, et al. Efficacy and safety of strontium ranelate in the treatment of knee osteoarthritis: results of a double-blind, randomised placebo-controlled trial. Ann Rheum Dis 2013;72:179-86.

26. Pelletier JP, Roubille C, Raynauld JP, et al. Disease-modifying effect of strontium ranelate in a subset of patients from the Phase III knee osteoarthritis study SEKOIA using quantitative MRI: reduction in bone marrow lesions protects against cartilage loss. Ann Rheum Dis 2013. Published Online First 2 Dec 2013. doi:10.1136/annrheumdis2013-203989

27. Bruyere O, Reginster JY, Bellamy N, et al. Clinically meaningful effect of strontium ranelate on symptoms in knee osteoarthritis: a responder analysis. Rheumatology 2014;53:1457-64.

28. Hellio le Graverand MP, Clemmer RS, Redifer P, et al. A 2-year randomised, double-blind, placebo-controlled, multicentre study of oral selective iNOS inhibitor, cindunistat (SD-6010), in patients with symptomatic osteoarthritis of the knee. Ann Rheum Dis 2013;72:187-95.

29. Schnitzer TJ, Ekman EF, Spierings EL, et al. Efficacy and safety of tanezumab monotherapy or combined with non-steroidal anti-inflammatory drugs in the treatment of knee or hip osteoarthritis pain. Ann Rheum Dis 2014. Published Online First: 13 Mar 2014. doi:10.1136/annrheumdis-2013-204905 